\title{
A CASE OF OUTSOURCING IN THE PHENOLIC RESIN INDUSTRY
}

\author{
Sílvio R. I. Pires \\ Methodist University of Piracicaba-sripires@unimep.br \\ Hercules B. Vernalha \\ FAAT-Atibaia Colleges- hbvernalha@uol.com.br \\ BRAZIL
}

\begin{abstract}
There is still a lack of studies related to the outsourcing process in several important non-leading industries worldwide and also regarding the existence of practical models and frameworks to guide the entire process and not only the decision-making stage. The article presents a practical model to conduct the whole outsourcing process, divided into four main stages (motivation, decision, implementation and management). It was successfully applied in a case involving two multinational companies operating in Brazil, in a supply chain of the phenolic resin industry. The results highlighted mainly the adequacy of the proposed model, as well as the importance of constructing a partnership based on trust and integration by information technology.
\end{abstract}

\section{INTRODUCTION}

Strong competition and increasing demand for quality and innovation in global markets are driving companies around the world to search for non-traditional ways to improve their capabilities. In order to reduce costs and gain flexibility, partners are strengthening their relationship along the supply chain thus concentrating resources on their own core competencies.

Information technology has provided conditions for the development of new management practices that support the process of networking with other companies in a well-coordinated supply chain or even in a virtual enterprise. Important business management tools like VMI (vendor-managed inventory), ECR (efficient consumer response) and ESI (early supplier involvement) are deeply dependent on electronic data interchange (EDI). EDI implementation over the Internet yielded more flexibility and operational simplicity for interconnecting companies.

In the last decade, manufacturing organizations in the automotive, electronic and computer industries have intensified their search for strategic and broader initiatives like the manufacturing activities outsourcing. A series of reasons have led companies to outsource those activities in the so-called non-core areas. Differently than subcontracting, in which secondary activities are delegated to external companies through easily reversible agreements, outsourcing initiative means compromise and divestment of resources and competencies to another company. 
Nowadays, industries considered non-leading in terms of advanced business practices, like the Chemical Processing Industry (CPI), are also trying to achieve competitive advantages by reinforcing their partnerships and focusing their managerial energy on their core competences. Manufacturing activities outsourcing is no longer a hard to find initiative in the CPIs in many countries, including Brazil. Nevertheless, there are very few reports regarding those experiences.

Outsourcing initiative demands different managerial skills since it integrates several management functions like Strategic Planning, Finance, Logistics and Human Resources. The contribution of each function changes along the outsourcing implementation, since different features take place at each phase of the process. This work presents a four-stage model for studying and conducting the whole outsourcing process. The stages are: Motivation, Decision Making, Implementation and Management.

Later in this paper, a manufacturing outsourcing initiative in the phenolic resin industry is studied in view of that four-stage proposal. Risks, options and solutions detected along the process are highlighted in order to point out the main features and challenges in each stage.

\section{SUPPLY CHAIN MANAGEMENT PRACTICES}

Rapid technology evolution and increasing competition in global markets put high pressure on companies to reduce costs, reduce time to market, improve quality and speed up innovation for complex products and services (Fürst \& Schmidt, 2001). The solution found by many firms in different industries to achieve those challenges was implementing a well-coordinated Supply Chain in order to establish virtual business units. Pires (1998) states SCM practices as the search for the benefits of Vertical Integration without its harmful consequences on costs and flexibility.

Manufacturing activities outsourcing demands very close and consonant partners relationship, which is often achieved by means of SCM practices. Among those practices, VMI (vendor-managed inventory) and ESI (early supplier involvement) were intensely involved in the process of implementation of outsourcing in the case studied.

\subsection{VMI - Vendor Managed Inventory}

The American Production and Inventory Control Society (APICS) defines VMI as "a means of optimizing supply chain performance in which the supplier has access to the customer's inventory data and is responsible for maintaining the inventory level required by the customer...VMI is accomplished by a process in which resupply is done by the vendor trough regularly scheduled reviews of the on-site inventory" (Flavin, 2002).

Following the definition above, one could find that VMI is easily performed without any IT (information technology) support. Waller et al. (1999) points that successful implementation of VMI often depends on computer platforms, communication technology, and product identification and tracking systems. He asserts that EDI alone provides little improvement in warehouse stockouts or inventory levels, but coupled with VMI it has been found to be very effective. 
Electronic controlled VMI becomes even more reliable and easily implemented when working with liquid material stocked in bulk. In this case, a liquid level transmitter installed in the product tank informs company MRP about any level changes inside the tank, on line, as shown in Figure 1.



Figure 1 - VMI in Tank Stored Products

The supplier can access customer inventories through EDI and replenish the customer tank as soon as the restocking level is reached, according to the tank capacity or to a maximum predefined level.

However, more than accessing inventory information, its necessary that suppliers be given information about customer market tendencies in order to assure a smooth and efficient supply. When restocking, minimum and maximum levels are adequately defined and supplier is informed about any significant changes in customer market behavior, VMI will allow both customer and supplier to achieve many advantages like reducing cost, increasing replenishment accuracy and making the resuppling process faster and less complex.

\subsection{ESI - Early Supplier Involvement}

In the last two decades, the involvement of suppliers in the process of developing new products became sooner and more profound due to the search for integrating supplier competences in the product design.

Bidault et al. (1996) point automotive industry practices in Japan as the origin of the cooperative attitude between customers and suppliers that developed ESI. They states that certain factors leading to ESI adoption, like competition and national culture, are external to the organization, while others relate to internal strategic or operational issues like level of integration and globalization.

The framework proposed by Calvi et al. (2001) presents a matrix based on the autonomy of the supplier in the development process and the development risk. They detect five types of suppliers' involvement, from the classic subcontracting relationship to the critical co-development. During the manufacturing activities outsourcing process, the close relationship between customer and supplier creates 
adequate environment for the product improvement or even the co-development of new products.

\subsection{Manufacturing Outsourcing}

Although the changing environment increases performance requirements and imposes constraints, it provides, at the same time, opportunities for exploiting resources meeting business demands (Dekkers, 2000). Manufacturing outsourcing is a growing practice among the companies that search for upgrading their capabilities to achieve more competitive advantages.

Ehie (2001) states that manufacturing outsourcing refers to the process of determining which of the manufacturing activities should be transferred to a thirdparty provider. The essence of outsourcing is the use of production facilities of other firms rather than using existing company resources or making new manufacturing investments. It is a complex initiative that demands different managerial functions during the whole outsourcing process, from the decision-making phase to the fully implemented process management.

This article proposes a four-stage model to the outsourcing process, aimed at facilitating the identification of features, risks and challenges that are present in each one of them. Figure 3 shows the sequential disposition of the stages, which are described below:

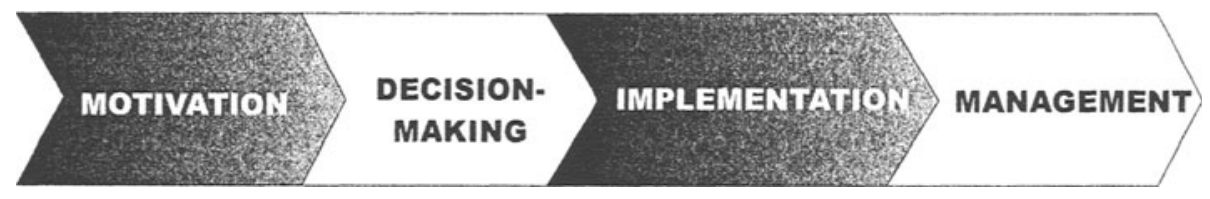

Figure 2 - Outsourcing Four-Stage Division

(a) Motivation: Defining the drivers for outsourcing often results from strategic or tactical planning that can deeply affect company performance. When an opportunity for outsourcing is correctly identified it allows a firm to focus on its core competences, thus providing more value for its products and a possibility for reducing its costs. On the other hand, outsourcing a strategically or critically important activity can lead the company into serious difficulties.

The Outsourcing Institute, in a 1995 survey, identified 10 major reasons why companies outsource. Based on that result, Ehie (2001) conducted a survey in which 108 American manufacturers were asked about their reasons for outsourcing. Results are shown in Figure 3.

(b) Decision: Very important decisions that involve strategic, technical, financial and logistic features take place in this stage of the process. Since outsourcing is a long-term agreement, choosing a solid, capable and trustworthy partner is a decisive step towards a successful partnership.

Another important choice is related to the kind of outsourcing contract to be adopted. Lumpsum contracts allow the customer to avoid over cost but, on the other hand, they demand more time dedicated to the development of a very precise and complete description of the purpose of the contract. Reimbursable contracts, in turn, 
allow changing the work scope, but also increase customer risks of over cost and exceeding schedule deadlines.

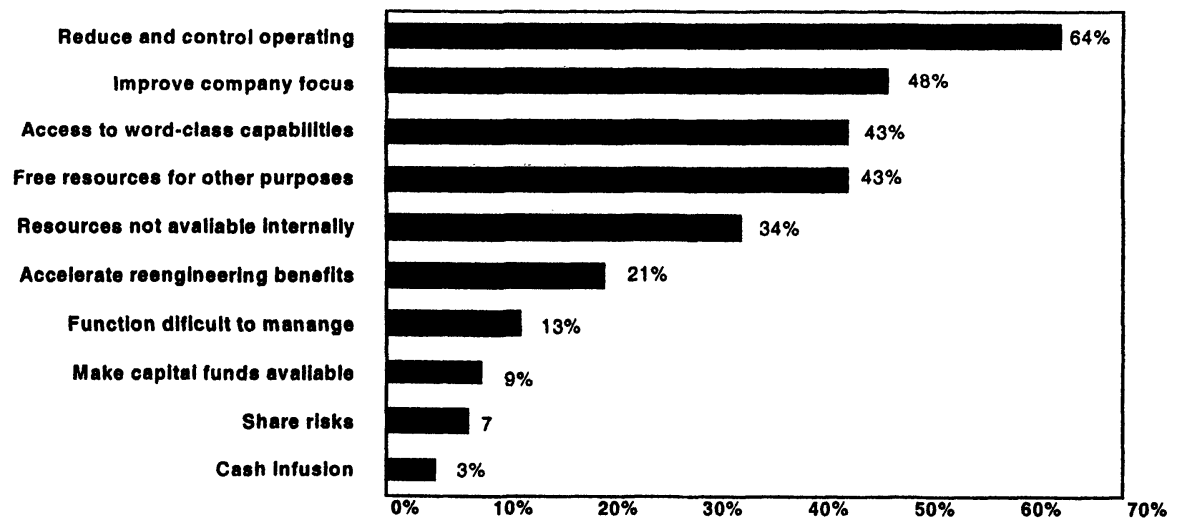

Figure 3 - Reasons for Outsourcing Decisions (Ehie, 2001)

(c) Implementation: Outsourcing implementation demands unlearning and relearning several concepts on resource management. Both supplier and customer companies will have to work together to face new challenges on production planning, raw material and finished goods logistics and costing. Motivating workers to share information and skills is also an important step in this stage. Information Technology is an essential tool to support performance of the new activities by helping the integration between customer and supplier.

(d) Management: Long-term outsourcing management, in turn, should assure continuous outsourcing benefit improvement through frequent assessment of the process and also researching new ways to keep the outsourcing initiative interesting and profitable. New management models should be developed along with the outsourcing process to ensure efficient management of purchase, contracts and logistic information.

\section{A CASE OF OUTSOURCING IN THE PHENOLIC RESIN INDUSTRY}

In the mid '90s, Borden Chemical Co. took several strategic decisions in order to improve its operations in Brazil. As a result of this plan, it was defined to shut down one of the company plants, located in Cotia (São Paulo State), where it manufactured phenol-formaldehyde novolac resin for friction and abrasive applications, among other products. Borden's managerial team decided to outsource this novolac resin (friction phenolic resin) production to the Schenectady Co. affiliate in Brazil (Schenectady Brasil Ltda). The outsourcing initiative was studied in light of the four-stage model presented above, from 1999 to 2001. In this period, it was possible to accompany the main aspects of the first three stages of the process, as follows. 


\subsection{Motivation}

The main drivers for Borden to outsource the phenol-formaldehyde resin manufacturing were:

- Focusing manufacturing operation on a more similar product portfolioBorden's strategic planning included the division of the Brazilian Affiliate into two companies, Alba Adesivos Ind. e Com. Ltda and Borden Química Industria e Comércio Ltda. Borden Química modernized its installations in Paraná State, where it has focused investments and established the largest formaldehyde plant in Latin America. In Paraná, Borden also manufactures formaldehyde-based resin for wood and furniture industries.

- Avoiding investing in Process Technology- Cotia Plant did not come along with the modernizing process described above. For remaining competitive in the friction phenolic resin market, Borden would have had to invest in equipment, automation and IT.

- Expenses Reduction- Sharing production facilities with another resin manufacturer would allow both companies to reduce labor, utilities, effluent water treatment and raw material expenses. Fixed expenses would be virtually eliminated by shutting down Cotia Plant.

On the other hand, the main driver against friction phenolic resin outsourcing was the high risk of loosing the business to the supplier.

\subsection{Decision Making}

Borden Química chose Schenectady Brasil Ltda. (SBL), a producer of phenolic resin, varnishes and enamels, for outsourcing its friction phenolic resin manufacturing in late 2000, although their first visit to SBL Plant in Atibaia (São Paulo State) happened in 1998. The main reasons for choosing SBL were:

- Accessing better capabilities: SBL plant facilities would allow Borden Química to improve its friction phenolic resin by providing it better technical resources like being grinded at lower temperature or even flaked. Moreover, SBL reactors were monitored and controlled through PLC based system and could also reach higher temperatures than those in Cotia Plant.

- Reliability of Supplier: Borden and Schenectady are both solid American multinational companies with very good relationship in USA and Brazil, although they are competitors in some product lines including friction phenolic resins. Even when Schenectady Inc. announced the purchase of a majority shareholding of Crios Resinas Sinteticas S.A. (in November, 2000), a considerable Brazilian competitor in friction phenolic resin line, Borden Management kept on trusting in the SBL confidentiality.

According to the reimbursable outsourcing contract adopted for a five-year period, Borden would be responsible for supplying raw materials for the friction phenolic resin production. 


\subsection{Implementation}

The main difficulties noticed during this stage were related to poor communication and data interchange between the two companies. Since phenolic resin production in Cotia plant was shut down in February 2001, the whole Borden friction phenolic resin manufacturing was outsourced to the SBL plant in Atibaia. It meant an expressive increase of the total plant production. At the beginning of the manufacturing outsourcing, existing IT infrastructure was not effective in supporting new activities regarding logistics and costing. The main features in this implementation stage are discussed bellow:

- VMI Practice: The most important liquid raw materials in the Atibaia plant are kept in storage tanks and restocked through EDI connection with the suppliers. Since Borden and SBL were not EDI-connected, raw material supplying management got more complex and expensive as outsourcing started. Some costly oversupply and lack of raw material occurrences were experienced in the beginning of the process.

- Production Planning: Conciliating both Borden and SBL schedules in the Atibaia facilities was an important challenge for the outsourcing management team. Borden sales broken information and the lack of access to SBL master production schedule were soon recognized as the major problems for achieving a consistent and accomplishable production planning.

In order to solve the problems dependent on IT support described above, SBL started studying to enhance its Enterprise Resource Planning (ERP) system with a Supply Chain (SC) module or even moving to a more powerful ERP system. Internet accessibility for suppliers and carriers was considered as a demand for the new system, which should operate with Extensible Markup Language (XML) to assure users a platform independent language that could work with a standard Web browser, as shown in Figure 4. ERP system adopted by Schenectady Inc. plants in USA was considered since its SC Module had just been enhanced to support standard XLM format to facilitate integration with customers, carriers and suppliers.

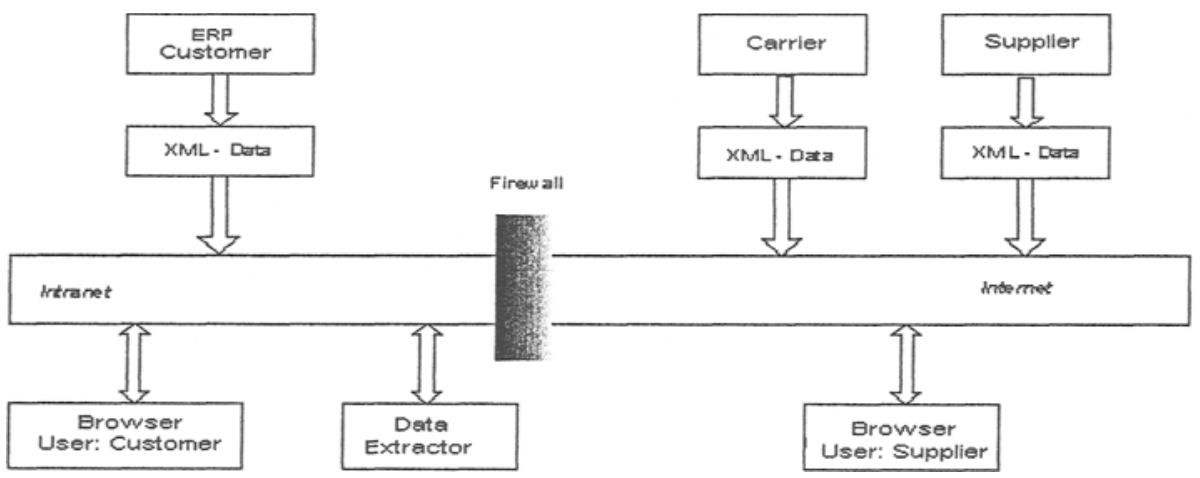

Figure 4 - System architecture (based on Fürst \& Schmidt, 2001)

Along the outsourcing implementation stage, as technical people from both companies met to learn each others product and process technology, a large number of improvements were achieved as a result of the synergy of the capabilities. It 
became quite clear that new products could be co-developed by the two technical teams working together.

\section{CONCLUSIONS}

Manufacturing outsourcing four-stage model has helped to emphasize the main challenges in each phase of the process studied as well as the abilities for facing them. The reasons for outsourcing initiative detected in the case study, like improving company focus and reducing operating costs, are easily found in the existing literature. On the other hand, factors unusually found, like company culture and national origin, were noticed as important drivers for outsourcing supplier choice in the decision-making stage. IT support appeared as a main factor for both companies to achieve a consistent production scheduling and also to connect specific tasks and processes. IT system configuration should be previously defined in order to avoid information exchange problems during the implementation stage.

A research on the long-term management stage aspects of an outsourcing case at the CPI is indicated for future works, since this study covered only the three first stages of the process. Special attention should be dedicated to the cooperation opportunities between customer and supplier in developing new products during this further stage.

\section{REFERENCES}

Bidault F, Despres C, Butler C. New Product development and Early Supplier Involvement ESI): The drivers of ESI adoption. In: Proceedings of the Product Development Management Association International Conference, 1996, Orlando, Florida....

Calvi R, Le Dain M, Harbi S, Bonotto VM. How to manage early supplier involvement (ESI) into the new product development process (NPDP) - several lessons from a French study. In: Proceedings of the The $10^{\text {th }}$ International Annual IPSERA Conference, 2001, Jönköping, Sweden.

Dekkers R. Decisions models for outsourcing and core competencies in manufacturing. International Journal of Production Research 38, no. 17, Nov 2000, pp. 4085 - 4096.

Ehie Ike C. Determinants of success in manufacturing outsourcing decisions: a survey study. Production and Inventory Management Journal, Jan 2001, pp.31-38

Flavin, John. Who's pulling your chain? AIAG - Action Line. Aug. 2002. http://www.aiag.org/ actionline/articles/aug02.html.

Fürst K, Schmidt T. Turbulent markets need flexible supply chain communication. Production Planning \& Control 12, no.5, Jul. 2001, pp.525-533.

Pires, Sílvio RI. Supply Chain Management. http:www.guiadelogistica.com.br/ARTIGO232.htm, 1998

Waller M, Johnson ME, Davis T. Vendor-managed inventory in the retail supply chain. Journal of Business Logistics, 2001. http://www.edm1.com/vmi_retail_sc.pdf 